\title{
A Inserção das Maiores Economias da África Subsaariana no Sistema Capitalista Contemporâneo: uma Leitura à Luz da Teoria de Rosa Luxemburgo
}

\section{The Inclusion of Sub-Saharan Africa into the Contemporary Capitalist System: an Approach in the Light of Rosa Luxembourg's Theory}

\author{
Cássio da Silva Calvete ${ }^{\text {a }}$ (iD \\ Joana Soares Cordeiro Lopes ${ }^{b}$ (iD
}

\begin{abstract}
Resumo: O presente artigo busca analisar a teoria da acumulação primitiva continuada de Rosa Luxemburgo e sua utilização para a análise das seis principais economias da África subsaariana nos dias de hoje. Com a entrada do século XXI, constata-se um renovado interesse das grandes potências em relação às riquezas e aos mercados dessa região. Essa nova corrida sucede em função da possibilidade de acumulação de capital que o ambiente africano ainda hoje proporciona. A partir do estudo das suas relações comerciais e estruturas produtivas, constata-se que os seis países selecionados ainda são externamente dependentes e subjugados ao mercado global como, em geral, meros exportadores de bens primários, dinâmica na qual se mantêm as relações imperialistas com o centro capitalista. Busca-se com esse artigo, portanto, verificar a hipótese de que a teoria de Rosa Luxemburgo pode ser aproximada ao caso desses países africanos nos dias de hoje e classificar em qual dos três estágios propostos pela autora eles se encontram: economia natural, mercantil ou capitalista.
\end{abstract}

Palavras-chave: Rosa Luxemburgo. Imperialismo na África. África subsaariana.

\begin{abstract}
This article seeks to analyze the theory of the continuing primitive accumulation of Rosa Luxembourg and its use for analysis of sub-Saharan Africa nowadays. With the entry of the 21st century, there is a renewed interest of the great powers in relation to African wealth and markets. This new race takes place due to the possibility of accumulation of capital that the African environment still provides today. Based on the study of the trade relations and productive structures of Africa, it is noted that the continent is still externally dependent and subjugated to the global market as, in general, a mere exporter of primary goods, dynamics in which imperialistic relationships are maintained with the Capitalist Center. This article therefore seeks to verify the hypothesis that Rosa Luxembourg's theory can be approximated to the African case today and to classify in

a Universidade Federal do Rio Grande do Sul (UFRGS), Faculdade de Ciências Econômicas (FCE), Departamento de Economia e Relações Internacionais (DERI). Rio Grande do Sul, Porto Alegre, Brasil.

b Universidade Federal do Paraná, Departamento de Economia. Curitiba, Paraná, Brasil.
\end{abstract}


which of the three stages proposed by the author is sub-Saharan Africa: natural, mercantile or capitalist.

Keywords: Rosa Luxemburg. Imperialism in Africa. Sub-Saharan Africa.

JEL Classification: F54; F59; O55.

\section{1 lntrodução}

O presente artigo se propõe a analisar a teoria da acumulação primitiva continuada de Rosa Luxemburgo (1871-1919) e sua aplicação em seis países selecionados da África subsaariana nos dias de hoje. A entrada do século XXI trouxe consigo um renovado interesse das grandes potências em relação às riquezas e aos mercados dessa região. É possível ver grandes similaridades do momento presente com o registrado por Rosa Luxemburgo no final do século XIX e início do século XX. Essa nova corrida para a África mantém o padrão de dominação sobre o continente - externamente dependente e subjugado ao mercado global. Busca-se com este artigo a validade da hipótese de que a teoria de Rosa Luxemburgo pode ser aplicada aos seis países africanos selecionados nos dias de hoje e classificar em qual dos três estágios propostos pela autora encontram-se: economia natural, mercantil ou capitalista.

Rosa Luxemburgo nasceu na Polônia em 1870, todavia foi na Alemanha que se tornou mundialmente conhecida. Ferrenha militante, destacou-se como líder política e intelectual da militância revolucionária ligada ao movimento socialista da classe operária alemã. Participou ativamente do Partido Socialista da Alemanha e fundou a Liga Espartaquista, quando, segundo ela, o partido não representava mais as demandas da verdadeira esquerda. Rosa Luxemburgo literalmente viveu e morreu pelo que acreditava (SINGER, 1984).

A partir da análise da teoria marxista da acumulação primitiva, Rosa Luxemburgo desenvolveu sua própria teoria da acumulação primitiva continuada, que acabou por gerar um estudo das bases econômicas do imperialismo. Luxemburgo viveu o auge da partilha da África pelas potências europeias e o acirramento das tensões imperialistas que levaram o mundo à Primeira Guerra Mundial. A teoria imperialista de Rosa Luxemburgo é extremamente rica e, ainda hoje, constitui importante paradigma para o estudo do imperialismo e da dinâmica capitalista. Dessa maneira, a segunda seção do presente trabalho dedica-se a detalhar e analisar a teoria de Rosa Luxemburgo presente em seu livro de 1913, A acumulação de capital, destacando-se passagens nas quais a autora utilizou estudos de caso da África.

Em seguida, na terceira seção, intitulada "A África e o imperialismo", busca-se analisar o papel da África na dinâmica econômica mundial através de uma 
perspectiva histórica. A partir de uma breve contextualização, percebe-se como o imperialismo pautou as dinâmicas africanas. Busca-se demonstrar como o papel africano de exportador de bens primários de baixo valor agregado se manteve desde a partilha da África vista por Rosa Luxemburgo no século XIX até a nova corrida registrada no século XXI, a partir de revisão de autores que se dedicam ao tema.

A quarta seção almeja analisar o perfil econômico de seis países selecionados da África subsaariana a fim de evidenciar suas relações com o mercado global. Esses dados e estudos de caso são utilizados para embasar e sustentar o argumento de que a África continua dominada por relações imperialistas ${ }^{1}$ que a mantêm numa posição subordinada no mercado global. Por fim, na quinta seção encontram-se as considerações finais do trabalho.

\section{A Teoria da Acumulação de Capital de Rosa Luxemburgo ${ }^{2}$}

Em seu livro de 1913, A acumulação de capital, Rosa Luxemburgo parte da análise do esquema de reprodução ampliada de Marx para chegar a uma explicação das bases econômicas do imperialismo. A teoria marxista presume a existência de somente duas classes na sociedade - capitalistas e trabalhadores - sob o domínio da forma de produção capitalista. Nessa sociedade, os trabalhadores gastam seus salários em consumo e os capitalistas utilizam sua mais-valia para consumo e acumulação de capital. Todavia, é importante ressaltar que a lógica dos capitalistas é a de acumular cada vez mais. Desse modo, os capitalistas utilizam a mais-valia extraída para ampliar sua capacidade produtiva cada vez mais. Constroem novas máquinas para, com elas, construírem novas máquinas e, assim, ampliar constantemente a extração da mais-valia (LUXEMBURGO, 1970).

Rosa Luxemburgo mostra que um crescimento econômico equilibrado feito dessa maneira seria impossível. Nesse processo, a mais-valia acumulada se direciona ao setor I para produzir meios de produção, demandados pelo setor II, ${ }^{3}$ que, assim, produz maiores quantidades de bens de consumo. Esse maior volume de

$1 \quad$ Apesar de se tratar de países independentes e com autonomia formal em termos de política interna/externa, na prática há uma subsunção real dos seis países selecionados em relação aos países de capitalismo desenvolvido. Portanto, quando aqui se refere ao imperialismo contemporâneo, não está se referindo ao conceito de imperialismo no seu sentido original, que designava relações ocorridas no século XIX. O termo aqui faz referência a um novo tipo de relação que prescinde da dominação formal. Para maior aprofundamento dessa questão, ver: Bracking e Harrison (2003), Bush e Szeftel (1999), Harvey (2013), Lee (2006, 2009), Mariutti (2013), Melber (2009), Satgar (2009) e Southall e Comninos (2009).

2 A Teoria da Acumulação de Capital de Rosa Luxemburgo também sofre críticas e reparações. No entanto, mesmo os críticos ressaltam a enorme importância do legado de Rosa Luxemburgo para o entendimento da acumulação de capital e do imperialismo, este trabalho não trata a respeito da crítica à obra da autora. O leitor que quiser conhecê-la deve buscar Robinson (1951), Miglioli (1981) e Hunt (2005).

3 O setor I produz meios de produção e o Setor II, bens de consumo (MIGLIORI, 1981).

Análise Econômica, Porto Alegre, v. 38, n. 76, p. 75-94, jun. 2020. 
produção, por sua vez, é redirecionado ao setor I, pois agora nesse departamento há um maior número de trabalhadores. Esse esquema anda em círculos e gera um desequilíbrio inevitável, pois a demanda por bens de consumo dos trabalhadores do setor I não cresce na medida da produção do setor II. Dessa forma, os capitalistas só podem continuar acumulando e ampliando sua produção se existir uma demanda crescente para a realização da mais-valia (MIGLIORI, 1981).

Segundo Luxemburgo (1970), a contradição desse esquema está na relação entre a capacidade ilimitada de expansão da força produtiva e a capacidade limitada de expansão do consumo social sob o domínio da economia de mercado, e, por isso, não pode haver uma sociedade dominada total e exclusivamente pelo capitalismo. A única soluçka contradição é que a realização da mais-valia se faça por compradores de fora da sociedade capitalista, ou seja, oriundos de modos de produção pré-capitalistas.

Rosa Luxemburgo esperava demonstrar dessa maneira que era estritamente necessário que o capitalismo estivesse em constante expansão, sempre conquistando novos mercados não capitalistas, ou seja, sendo imperialista. A demanda crescente necessária para a realização da mais-valia, citada anteriormente, viria então dos mercados externos, que são, segundo a autora, as zonas não capitalistas que absorvem os excedentes da produção e fornecem operários e matérias-primas. Uma vez que Luxemburgo redefine o conceito de mercado externo, o mercado interno também adquire nova conotação, o qual seria o próprio mercado capitalista. Dessa maneira, trocas econômicas entre dois países capitalistas como Inglaterra e Alemanha constituiriam um mercado interno, enquanto que a troca entre a indústria inglesa e consumidores camponeses ingleses, ainda pré-capitalistas, seria um exemplo de mercado externo (LUXEMBURGO, 1970).

Marx tratou da importância dos mercados externos em sua análise sobre a gênese do capitalismo, ou seja, a fase da acumulação primitiva. Rosa Luxemburgo, entretanto, vê esse processo como a base do funcionamento da economia capitalista. O imperialismo seria a extensão da acumulação primitiva de Marx. Para a autora, a acumulação primitiva não é apenas uma fase inicial do capitalismo, a acumulação primitiva seria uma característica intrínseca da acumulação de capital, válida desde o ponto de partida do capitalismo até seu fim, por isso ela a chama de acumulação primitiva continuada (HUNT, 2005).

O capitalismo, portanto, surge e se desenvolve historicamente cercado por formas de produção não capitalistas. É esse ambiente que garante a acumulação de capital e o capitalismo dele necessita para sua própria existência e desenvolvimento. O imperialismo constitui, então, a expressão política desse processo. As economias naturais se baseiam em comunidades autossuficientes que produzem em função da própria necessidade doméstica. Nesse modo de produção, não existe demanda por produtos estrangeiros e a estrutura social da comunidade consti- 
tui um obstáculo para a inserção da economia capitalista. Assim, o primeiro passo do capital é aniquilar sistematicamente as estruturas sociais não capitalistas para poder apropriar-se violentamente de seus meios de produção e de suas forças de trabalho e, dessa forma, transformá-la em uma economia mercantil, consumidora de mercadorias capitalistas (LUXEMBURGO, 1970).

O método violento utilizado pelo capital é consequência direta do embate entre o capitalismo e as estruturas da economia natural que entravam sua acumulação. Para destruir essas economias, o capitalismo faz uso da força política e militar, da tributação opressiva, da concorrência comercial, entre outros instrumentos. Essas medidas têm o objetivo de transformar a economia natural em uma economia especializada na produção de poucos tipos de bens para forçá-la a depender do comércio com o mundo capitalista (MIGLIORI, 1981).

Rosa Luxemburgo utiliza como exemplo da quebra da economia natural a história da política francesa na Argélia. Grande parte do território argelino era regido por tribos árabes onde reinavam costumes patriarcais primitivos. As normas dessas comunidades se baseavam em laços muito estreitos de solidariedade, auxílio mútuo e igualdade. Assim que os franceses converteram a Argélia em colônia, a obra "civilizatória" foi iniciada. Como primeira medida, foi empreendida a destruição sistemática da propriedade comum das famílias árabes e sua subsequente partilha. A maior parte das terras cultiváveis passou para o Estado francês, que as empregou para a colonização, reduzindo, assim, as tribos a um território cada vez menor. Eventualmente, os árabes conseguiam readquirir suas terras, mas, para isso, contraíam grandes dívidas, que eram aprofundadas com a pressão fiscal francesa. Além disso, por anos os franceses tentaram impor violentamente a propriedade privada burguesa sobre as comunidades primitivas, o que resultou em ainda mais pilhagem e aniquilação dos territórios das tribos e das grandes famílias (LUXEMBURGO, 1970).

Nesse processo de transformação da economia natural em mercantil, a introdução dos meios de transporte e de comunicação constitui condição vital para a difusão do capitalismo em regiões de economia natural. Além de facilitarem as trocas de mercadoria, os transportes modernos, como as estradas de ferro, e os meios de comunicação, como as linhas telegráficas, constituem um modo do capitalismo realizar parte de sua produção. O caráter pacífico dessas iniciativas é ilusório, uma vez que contribuem para a quebra da economia natural e a incorporação da mão de obra local ao capital (LUXEMBURGO, 1970).

A última fase apontada por Rosa Luxemburgo na luta contra a economia natural é separar as atividades artesanais da agricultura, ou seja, eliminar as indústrias rurais da economia rural. $\mathrm{Na}$ economia rural, o artesanato tem papel essencial para satisfazer as necessidades domésticas. Para que haja demanda por mercadorias, o desenvolvimento capitalista busca a redução da economia rural a um só ramo: a 
agricultura. Essa especialização faz com que o fazendeiro tenha que vender sua produção para ter dinheiro, do qual pouco precisava antes, para assim poder pagar seus impostos e adquirir mercadorias industriais (LUXEMBURGO, 1970).

Historicamente, o capitalismo se desenvolve cercado por meios sociais não capitalistas. No começo do seu desenvolvimento na Europa, o capitalismo nasce rodeado pela estrutura feudal e, posteriormente, por um modo de produção simples, com predominância da agricultura e do artesanato. Nesse meio se dá a acumulação primitiva do capitalismo. A partir desse pontapé inicial, Rosa Luxemburgo define três fases da acumulação das economias capitalistas: "[...] a luta do capital com a economia natural, a luta com a economia de mercado, e a luta pela concorrência do capital no cenário mundial para conquistar o resto dos elementos para a acumulação [...]" (LUXEMBURGO, 1970, p. 317).

A história da África do Sul mostra bem a questão da vitória do capital sobre a pequena economia rural. Os bôeres, descendentes de colonizadores holandeses que se estabeleceram no sul da África, lá viviam assentados sobre uma economia natural baseada na escravização das tribos indígenas. Apesar de serem europeus, a sua dominação não trouxe o modo de produção capitalista para o território sulafricano, esse chegou com os ingleses. No ano de 1880, a Inglaterra travou uma guerra contra os bôeres sob a justificativa da emancipação dos negros africanos. Todavia, a verdadeira motivação para essa guerra era a busca dos ingleses por mais terras, mais capacidade de trabalho e mais recursos naturais. Essa guerra era, na realidade, uma luta entre camponeses e a política colonial do grande capitalismo, que foi vencedor (LUXEMBURGO, 1970).

Outros instrumentos econômicos também são usados pelo capitalismo para a conquista ou preservação de seus mercados externos. O método mais importante é os empréstimos internacionais, os quais são imprescindíveis para a emancipação dos novos Estados capitalistas. Entretanto, ao mesmo tempo em que ajudam esses países, os empréstimos também são a garantia mais segura dos Estados capitalistas mais antigos de continuarem controlando a economia dos mais novos. Além disso, os empréstimos podem servir de barganha para a negociação de abertura comercial, políticas alfandegárias e campos de investimento (LUXEMBURGO, 1970).

Os Estados capitalistas antigos manipulam os novos para que, com os empréstimos, seus excedentes de produção sejam comprados. Outro estudo de caso que Rosa Luxemburgo faz, também sobre a África, é o do Egito. Nesse país perdurava um sistema de vassalagem centrado na figura do quediva, o soberano egípcio. Esse sistema era primitivo e patriarcal até que, em 1830, a série dos grandes empreendimentos capitalistas foi iniciada. O capital francês executou as obras de canalização do Nilo, que se mostraram inúteis, e do Canal de Suez, que condenou o Egito à submissão ao capital europeu. Para a construção do Canal, o país forne- 
ceu trabalho gratuito por anos e contraiu uma dívida pública gigantesca (LUXEMBURGO, 1970).

Todavia, a maior revolução na economia egípcia foi o empreendimento das plantações de algodão. Durante a Guerra de Secessão americana, o preço do algodão subiu repentinamente e, como consequência, iniciou-se uma febre de plantações algodoeiras no Egito. Para a aquisição de máquinas europeias modernas adequadas a essa plantação, foram contraídos empréstimos com países europeus, e esse cultivo alterou todos os procedimentos tradicionais da economia egípcia. Assim que a guerra acabou nos Estados Unidos, o preço do algodão rapidamente baixou e a produção egípcia colapsou, dando espaço a um novo produto: a cana-de-açúcar. Essa nova produção significou mais um volume imenso de máquinas sendo importadas e empréstimos sendo contraídos. A dívida pública do Egito subia a juros altíssimos para que os instrumentos fossem comprados e os meios de transporte necessários construídos. Assim, o capital europeu era acumulado enquanto o Egito exauria seus camponeses através da tributação excessiva em função de empreendimentos que enriqueceriam outros (LUXEMBURGO, 1970).

O último aspecto que Rosa Luxemburgo destaca em sua análise do imperialismo é o militarismo. Presente em todas as fases históricas da acumulação, o militarismo, além de ser uma arma na concorrência dos países capitalistas na disputa pelo domínio de regiões não capitalistas, também constitui um campo de acumulação: é em si mesmo um mercado externo. Rosa Luxemburgo considera o Estado como uma instituição sob controle dos próprios capitalistas e no qual os impostos incidem principalmente sobre a classe operária e o campesinato. Assim, quando o Estado emprega esses recursos para a compra de armamentos, a demanda por material de guerra cria um novo mercado e uma nova possibilidade de acumulação. Com os impostos, o poder de compra dos trabalhadores é diminuído, o que gera um decréscimo relativo na quantidade de meios de subsistência necessários para a renovação da força de trabalho. Dessa maneira, há um excesso de capital e trabalho vivo que pode ser alocado em outra produção se houver demanda. $\mathrm{O}$ Estado é que representa essa nova demanda possibilitada pela diminuição do poder de compra da classe trabalhadora adquirida através da tributação. O militarismo, então, é utilizado pelo capital para apropriar-se, através do colonialismo, dos meios de produção e das forças de trabalho das regiões não capitalistas, enquanto, dentro dos países capitalistas, priva os trabalhadores de seu poder de compra (LUXEMBURGO, 1970).

Rosa Luxemburgo termina sua análise condenando o capitalismo a um fim causado por si próprio. Quanto mais violentamente o militarismo age, destruindo as camadas não capitalistas, tanto interior como exteriormente, piores são as condições de vida dos trabalhadores e a história da acumulação no mundo torna-se cada vez mais destruidora. Isso, em conjunto com as crises econômicas periódicas, 
torna impossível a continuação da acumulação antes mesmo de seu esgotamento natural ao provocar a rebelião da classe operária internacional. Assim, o capitalismo se desenvolve de maneira a converter-se em forma de produção única no mundo. Entretanto, atingir esse objetivo significa o seu fim em si mesmo (LUXEMBURGO, 1970).

\section{A África e o Imperialismo}

A história do continente africano é marcada pela exploração. A busca predatória de agentes externos por recursos, territórios e pessoas está presente na sua história há quase 500 anos, iniciada na era do capital mercantil (SATGAR, 2009). Como é possível ver nos estudos de caso realizados por Rosa Luxemburgo em seu livro, a África constituiu um próspero mercado externo para onde os europeus podiam exportar seus excedentes, investir lucrativamente na construção de obras de transporte e comunicações, explorar recursos e mão de obra e controlar territórios como bem entendessem (LUXEMBURGO, 1970).

A África foi o principal destino da corrida imperialista do final do século XIX, e a partilha desse imenso continente ocorreu de forma sistemática, mas também afoita. A Revolução Industrial na Europa foi a grande geradora dessa corrida. A Inglaterra, a mais avançada nação capitalista, foi pioneira no desenvolvimento industrial e tornou-se o centro do poder econômico e político da época, controladora do mercado mundial. Os outros países europeus, cobiçando a superioridade inglesa, buscaram deter possessões coloniais para fomentarem o seu próprio desenvolvimento industrial, assim como fez a Inglaterra. Mais do que nunca, as potências europeias desejavam recursos naturais e mercados consumidores, o que despertou o interesse em conquistar novos territórios. Dessa maneira, a competição entre os países europeus produziu a lógica imperialista da colonização, uma vez que todos almejavam garantir seus territórios e evitar perdê-los para outro colonizador. A partir desse processo, foi realizada a partilha da África, sendo a Conferência de Berlim de 1884 e 1885 seu marco histórico (KRIPPENDORFF, 1979).

A expansão imperialista foi a maneira encontrada pelos países europeus para assegurar seu crescimento industrial. O capitalismo europeu pôde continuar desenvolvendo-se às custas da exploração da economia natural africana. Nessa lógi$\mathrm{ca}$, os europeus tomaram posse das ricas reservas de matérias-primas e destruíram os modos tradicionais de produção para criar o trabalhador assalariado, obtendo, assim, mão de obra barata. Essa foi a herança deixada à África pelas grandes potências do século XIX. Economias direcionadas ao enriquecimento do centro capitalista nas quais sua população e recursos são explorados violentamente (LUXEMBURGO, 1970). 
Todo esse processo ocorreu apesar da grande resistência africana à conquista europeia. Em um misto de guerras desiguais e de cooperação com populações locais, a Europa partilhou a África e enriqueceu às suas custas. A colonização suscitou o movimento nacionalista que defendia a independência e a própria consciência de uma identidade africana. No século XX, a nova ordem internacional do pós-Segunda Guerra trouxe consigo o movimento de descolonização e a gradativa independência das antigas colônias. Entretanto, apesar da liberdade política, muitas antigas colônias continuaram presas a laços econômicos muito fortes com suas antigas metrópoles. Esse processo de dependência e dominação por outros meios foi chamado de Neocolonialismo. Nesse contexto, além dos antigos dominadores, os Estados Unidos passaram também a ter presença marcante na África, disputando-a como área de influência com a União Soviética (SOUTHALL; MELBER, 2009). Com o fim da Guerra Fria, constatou-se uma drástica diminuição da presença e atenção dada ao continente por parte das grandes potências. A África perdeu a posição estratégica que tinha no mundo bipolar. O cenário de grande desigualdade econômica, disputas territoriais - muitas das quais causadas pela delimitação arbitrária de fronteiras pelos colonizadores - e fraco poder estatal em alguns países se tornou propício para o desencadeamento de guerras civis. Além das guerras, algumas regiões do continente africano também sofreram com a proliferação de doenças como o HIV/Aids, o baixo crescimento econômico, a crise da dívida e a pobreza generalizada. Assim, submissa aos ajustes neoliberais do Fundo Monetário Internacional e do Banco Mundial, a África viveu duas décadas perdidas (VISENTINI, 2013).

Com a entrada do século XXI, esse quadro se modificou. Registrou-se no continente africano um grande fluxo de investimento externo, aumento nas exportações e maiores índices de crescimento econômico. Por trás desses indicadores, está um renovado interesse externo pelos recursos e mercados africanos. Essa nova corrida pela África, apesar de apresentar uma dinâmica similar, inclui novos atores. Além dos Estados Unidos e dos antigos dominadores europeus, potências emergentes como os membros do Brics se destacam como novos parceiros comerciais (SOUTHALL; MELBER, 2009).

A África é um continente extremamente rico. A sua abundância em recursos naturais a condenou a ser alvo de interesses externos que pouco ou nada acrescentam ao seu desenvolvimento. O continente africano é cobiçado por seu ouro, ferro, aço, cobre, manganês, diamante, cobalto, bauxita, zinco, urânio, petróleo, gás natural e diversos outros recursos minerais (SARAIVA, 2015). Assim como no final do século XIX, a riqueza natural africana volta a ser objeto de intensas disputas entre países nesse início do século XXI, especialmente devido à emergência da China e sua enorme demanda por recursos minerais e energéticos. 
O aumento da demanda mundial por recursos, liderada pela China, gerou um maior crescimento econômico dos países africanos, que se especializaram nesses setores primários. Esse padrão de comércio no qual a África se insere é o tradicional padrão norte-sul. A histórica divisão internacional do trabalho coloca a África numa posição de exportadora de matérias-primas de baixo valor agregado e importadora de bens industriais e tecnológicos de maior valor. A contínua demanda externa por esses recursos a mantém subordinada a potências capitalistas e delas dependente, como esteve desde a entrada dos europeus no continente (SOUTHALL; MELBER, 2009). Nesse novo contexto, cabe questionar se a teoria de Rosa Luxemburgo da acumulação primitiva continuada e do imperialismo ainda é válida e pode ser aplicada à África nos dias de hoje. Também, é oportuno examinar em que estágio nos termos apresentados por Rosa Luxemburgo essa relação da África com as economias capitalistas centrais se apresenta: o continente ainda estaria exercendo o papel de economia natural? Teria evoluído para a condição de economia mercantil? Ou já estaria completamente integrado à economia capitalista e exercendo um papel de concorrência?

\subsection{Perspectivas Atuais}

O conceito de imperialismo é extremamente útil para a compreensão das relações econômicas e políticas da África com o resto do mundo. De acordo com Rosa Luxemburgo (1970), o imperialismo é a expressão política do processo de expansão do capitalismo na conquista de áreas não capitalistas. Uma vez que o centro capitalista necessita das periferias para se desenvolver, a economia africana serviu como solução para o desequilíbrio inevitável do modo de produção capitalista e, hoje em dia, ainda executa a função de mercado externo próspero. Isso se dá exatamente pelo papel da região na economia mundial de, no geral, mera fornecedora de matérias-primas e importadora de bens de maior valor agregado. $\mathrm{O}$ continente é um ambiente de grandes oportunidades e cuja possibilidade de crescimento abre espaço para o investimento externo. Dessa maneira, a África continua sendo explorada por agentes externos com pouca contrapartida de desenvolvimento interno. Como afirmam Bracking e Harrison (2003, p. 9), o imperialismo mostra como o capitalismo não se dedica ao desenvolvimento do continente, pelo contrário, constitui-se como "[...] uma história de dominação externa e formas de acumulação socialmente prejudiciais e voltadas para fora [...]". Assim, a natureza desigual do capitalismo continua criando estruturas desiguais de poder e riqueza que aprofundam os padrões de submissão já estabelecidos.

A partir desse processo complexo e desigual, a África de hoje, almejada por seus recursos e registrando maior presença externa, mantém-se restringida por laços imperialistas. A região ainda hoje constitui um mercado externo, nos marcos de Luxemburgo, onde a acumulação é facilitada pela extrema dependência 
entre o continente africano e o mercado mundial e pela dificuldade dos Estados africanos em voltarem políticas econômicas ao seu desenvolvimento. A "dádiva" da globalização, das medidas neoliberais e da divisão internacional do trabalho garante que ainda haja dominação do centro capitalista sobre a periferia, mesmo que não formalmente, em uma espécie de Neocolonialismo ainda no século XXI (BUSH; SZEFTEL, 1999). Os imperativos do mercado global colocam países como os africanos em uma posição submissa. Em um contexto em que as instituições do mercado e do Estado estão intrinsecamente atreladas, o desenvolvimento desigual do capitalismo no continente e as relações de dominação e controle vigentes impedem a ação autônoma dos Estados, uma vez que as decisões estão submetidas às necessidades do capital global. Para esses países, a globalização não foi uma escolha livre e consciente e a posição de produtores de bens primários para a exportação é a única ao alcance.

Dessa maneira, a África continua cercada pelo imperialismo, que, em sua fase contemporânea, deixa o continente ainda mais marginalizado em relação à economia global. A atual disputa pela região é caracterizada, por Lee (2006), como detentora de duas facetas - "salvando a África" e "imperialismo nu". A primeira seria constituída pelo discurso de que a África precisa de ajuda externa para vencer a pobreza e atingir o desenvolvimento e, por isso, os países contribuem para programas econômicos objetivando diminuir a marginalização africana, ao passo que a segunda faceta, imperialismo nu, representa a força destrutiva do capitalismo, que tudo explora em função da acumulação de capital. Essas são as intenções reais dos agentes externos que estão no continente, mascaradas pela bandeira de bom samaritano que almeja curar as mazelas africanas. A autora ressalta que, por trás do discurso bonito, falta o reconhecimento de que o alto padrão de bem-estar vivido nos países centrais se deve em grande parte à exploração gananciosa dos recursos desse território e que esse processo continua a criar economias insustentáveis. Não há ajuda humanitária que compense toda a exploração que o continente africano já sofreu.

Portanto, a África hoje continua atrelada a laços imperialistas que exercem dominação sobre ela, mesmo que não formalmente. Nessa configuração, a teoria de Rosa Luxemburgo do imperialismo, solução para a contradição inerente à economia capitalista, se mostra válida para explicar a condição africana nos dias de hoje. A grande busca pelos mercados e recursos no século XXI continua sendo intrinsecamente uma relação imperialista do centro capitalista com a periferia marginalizada.

Dentro dos parâmetros de Rosa Luxemburgo, considera-se que a África hoje está em transição, tendo áreas já incorporadas à economia capitalista, mas também regiões ainda não capitalistas e de economia mercantil. Nesse sentido, as áreas já convertidas ao capitalismo - processo realizado pelo capital estrangeiro em seu processo de expansão e acumulação desde o século XIX - estão integradas ao 
mercado global, mantendo relações comerciais com outras áreas do mundo. Existem também áreas de economia mercantil, a segunda etapa de Luxemburgo, ou seja, na qual já existem trocas capitalistas, porém sem desenvolvimento industrial. Além delas, as regiões não capitalistas, dominadas principalmente pela agricultura simples e de subsistência, estão sob pressão tanto das camadas capitalistas dentro de cada país quanto das forças externas. Acontece na África hoje um processo similar ao descrito na gênese do capitalismo, em que a expansão se deu dentro das próprias fronteiras nacionais dos países europeus. A esse processo soma-se a expansão dos países já capitalistas, que buscam acumulação nessas áreas, onde há, portanto, a possibilidade de acumulação via rompimento das economias naturais dentro dos Estados africanos. Dessa maneira, há diferentes estágios do processo de introdução da economia capitalista no continente africano. Nas seções seguintes, apresentam-se dados e estudos de caso que ilustram essas características das economias africanas.

\section{A Inserção de Seis Países Selecionados da África Subsaariana no Mercado Capitalista}

A partir da teoria de Rosa Luxemburgo, percebe-se que alguns dos objetivos do imperialismo são a obtenção de recursos para fomentar o desenvolvimento do centro capitalista, a constituição de campos de acumulação - através da construção de infraestrutura e do militarismo, por exemplo -, a apropriação de força de trabalho e a liquidação de excedentes. O tipo de relação comercial que se dá atualmente entre os países africanos e países de economia mais forte - tais quais os Estados Unidos, os países europeus e a China -, apesar de não constituírem dominação formal, ainda gera maiores benefícios para estes do que para aqueles.

É possível constatar, a partir da avaliação da balança comercial dos seis países estudados, que até as maiores economias do continente têm as relações comerciais pautadas na exportação de produtos primários e importação de bens de maior valor agregado. Como dito anteriormente, essa relação acentua a dependência externa e mantém esses países em uma posição de desvantagem competitiva na divisão internacional do trabalho. Para fins dessa pesquisa, serão avaliados os seis países de maior PIB da África subsaariana, ou seja, Nigéria, África do Sul, Sudão, Angola, Etiópia e Quênia. Ademais, os principais critérios foram divididos em dois quadros: no primeiro, informações relacionadas à estrutura produtiva interna dos países - composição do PIB por setor de origem, distribuição da força de trabalho nesses setores e composição da indústria; e, no segundo, informações sobre as relações comerciais - os principais bens exportados e importados e os principais parceiros de exportação e de importação. 
Quadro 1 - Países africanos selecionados e suas estruturas produtivas

\begin{tabular}{|c|c|c|c|}
\hline País & $\begin{array}{c}\text { Composição do } \\
\text { PIB }\end{array}$ & $\begin{array}{l}\text { Força de trabalho } \\
\text { por ocupação }\end{array}$ & $\begin{array}{l}\text { Composição } \\
\text { da indústria }\end{array}$ \\
\hline Nigéria & $\begin{array}{l}\text { Agricultura: } 21,2 \% \text {. } \\
\text { Indústria: } 18,4 \% \text {. } \\
\text { Serviços: } 60,4 \% \text {. }\end{array}$ & $\begin{array}{l}\text { Agricultura: } 70 \% . \\
\text { Indústria: } 10 \% . \\
\text { Serviços: } 20 \% .\end{array}$ & $\begin{array}{l}\text { Petróleo bruto, carvão, estanho, } \\
\text { columbita, produtos de bor- } \\
\text { racha, madeira,têxteis, cimen- } \\
\text { to, materiais de construção, } \\
\text { produtos alimentícios, calçados, } \\
\text { químicos, fertilizantes, cerâmica, } \\
\text { aço. }\end{array}$ \\
\hline África do Sul & $\begin{array}{l}\text { Agricultura: 2,4\%. } \\
\text { Indústria: } 29,0 \% \text {. } \\
\text { Serviços: 68,6\%. }\end{array}$ & $\begin{array}{l}\text { Agricultura: 4,6\%. } \\
\text { Indústria: } 23,5 \% . \\
\text { Serviços: 71,9\% }\end{array}$ & $\begin{array}{l}\text { Mineração (platina, ouro, cro- } \\
\text { mo), montagem de automóveis, } \\
\text { metalurgia, maquinaria, têxteis, } \\
\text { ferro e aço, químicos, fertilizan- } \\
\text { tes, processamento de alimentos, } \\
\text { reparo de navios. }\end{array}$ \\
\hline Sudão & $\begin{array}{l}\text { Agricultura: 39,5\%. } \\
\text { Indústria: 2,6\%. } \\
\text { Serviços: 57,9\%. }\end{array}$ & $\begin{array}{l}\text { Agricultura: } 80 \% . \\
\text { Indústria: } 7 \% . \\
\text { Serviços: } 13 \% .\end{array}$ & $\begin{array}{l}\text { Petróleo, algodão, têxteis, cimen- } \\
\text { to, óleos comestíveis, açúcar, } \\
\text { sabão, calçados, petróleo refina- } \\
\text { do, farmacêuticos, armamentos, } \\
\text { montagem de automóveis. }\end{array}$ \\
\hline Angola & $\begin{array}{l}\text { Agricultura: 10,2\%. } \\
\text { Indústria: } 61,4 \% \text {. } \\
\text { Serviços: } 28,4 \% \text {. }\end{array}$ & $\begin{array}{l}\text { Agricultura: } 85 \% . \\
\text { Indústria e serviços: } \\
\text { 15\%. }\end{array}$ & $\begin{array}{l}\text { Petróleo, diamantes, ferro, fos- } \\
\text { fato, feldspato, bauxita, urânio, } \\
\text { ouro, cimento, produtos de } \\
\text { metal básico, peixe processado, } \\
\text { alimentos processados, produtos } \\
\text { de tabaco, açúcar, têxteis. }\end{array}$ \\
\hline Etiópia & $\begin{array}{l}\text { Agricultura: 37,2\%. } \\
\text { Indústria: } 21,3 \% . \\
\text { Serviços: } 41,5 \% .\end{array}$ & $\begin{array}{l}\text { Agricultura: 72,7\%. } \\
\text { Indústria: 7,4\%. } \\
\text { Serviços: } 19,9 \% .\end{array}$ & $\begin{array}{l}\text { Alimentos processados, bebidas, } \\
\text { têxteis, couro, vestuário, quími- } \\
\text { cos, metal processado, cimento. }\end{array}$ \\
\hline Quênia & $\begin{array}{l}\text { Agricultura: } 35,7 \% . \\
\text { Indústria: } 17,2 \% \text {. } \\
\text { Serviços: 47,3\%. }\end{array}$ & $\begin{array}{l}\text { Agricultura: } 61,1 \% . \\
\text { Indústria: 6,7. } \\
\text { Serviços: } 32,2 \% .\end{array}$ & $\begin{array}{l}\text { Bens de consumo de pequena } \\
\text { escala (plástico, baterias, móveis, } \\
\text { têxteis, sabão, cigarros, farinha), } \\
\text { produtos agrícolas, produtos } \\
\text { hortícolas, petróleo refinado, } \\
\text { alumínio, aço, chumbo, cimento. }\end{array}$ \\
\hline
\end{tabular}

Fonte: Elaboração própria a partir de United States of America (2017).

Nota: As informações na sua grande maioria fazem referência ao ano de 2016 ou a anos próximos. No entanto, cabe destacar que os dados referentes aos percentuais de força de trabalho do Sudão são de 1998 e os da Nigéria são de 1999. 
Quadro 2 - Países africanos selecionados e suas relações comerciais

\begin{tabular}{|l|l|l|l|l|}
\hline País & $\begin{array}{l}\text { Principais pro- } \\
\text { dutos } \\
\text { exportados }\end{array}$ & $\begin{array}{l}\text { Principais par- } \\
\text { ceiros de expor- } \\
\text { tação }\end{array}$ & $\begin{array}{l}\text { Principais } \\
\text { produtos } \\
\text { importados }\end{array}$ & $\begin{array}{l}\text { Principais } \\
\text { parceiros de } \\
\text { importação }\end{array}$ \\
\hline Nigéria & $\begin{array}{l}\text { Petróleo e seus } \\
\text { derivados (95\%), } \\
\text { cacau, borracha. }\end{array}$ & $\begin{array}{l}\text { Índia (34,0\%) } \\
\text { Estados Unidos } \\
\text { África do Sul (7.8\%) }\end{array}$ & $\begin{array}{l}\text { Maquinário, pro- } \\
\text { dutos químicos, } \\
\text { equipamentos } \\
\text { de transporte, } \\
\text { Eens manufatu- } \\
\text { rados, alimentos, } \\
\text { animais vivos. }\end{array}$ & $\begin{array}{l}\text { China (20,3\%) } \\
\text { Estados Unidos }\end{array}$ \\
\hline $\begin{array}{l}\text { Bélgica (7,6\%) } \\
\text { Reino Unido }\end{array}$ \\
\hline Su,4\%)
\end{tabular}

Continua... 
Conclusão.

\begin{tabular}{|c|c|c|c|c|}
\hline País & $\begin{array}{l}\text { Principais pro- } \\
\text { dutos } \\
\text { exportados }\end{array}$ & $\begin{array}{l}\text { Principais par- } \\
\text { ceiros de expor- } \\
\text { tação }\end{array}$ & $\begin{array}{l}\text { Principais } \\
\text { produtos } \\
\text { importados }\end{array}$ & $\begin{array}{l}\text { Principais } \\
\text { parceiros de } \\
\text { importação }\end{array}$ \\
\hline Angola & $\begin{array}{l}\text { Petróleo bruto, } \\
\text { diamantes, } \\
\text { petróleo refinado } \\
\text { e seus derivados, } \\
\text { café, sisal, peixe, } \\
\text { madeira, algodão. }\end{array}$ & $\begin{array}{l}\text { China }(53,7 \%) \\
\text { Índia }(7,6 \%) \\
\text { Estados Unidos } \\
(5,6 \%) \\
\text { África do Sul }(5,3 \%) \\
\text { França (4.4\%) }\end{array}$ & $\begin{array}{l}\text { Maquinário, } \\
\text { equipamentos } \\
\text { elétricos, veículos } \\
\text { e peças automoti- } \\
\text { vas, medicamen- } \\
\text { tos, alimentos, } \\
\text { têxteis, bens } \\
\text { militares. }\end{array}$ & $\begin{array}{l}\text { Portugal }(15,9 \%) \\
\text { Estados Unidos } \\
(12,5 \%) \\
\text { China (12,2\%) } \\
\text { Coreia do Sul } \\
\begin{array}{l}\text { (11\%) } \\
\text { África do Sul } \\
(6,8 \%)\end{array} \\
\text { Bélgica (6,3\%) } \\
\text { Brasil (5,5\%) } \\
\text { Reino Unido } \\
(4,3 \%)\end{array}$ \\
\hline Etiópia & $\begin{array}{l}\text { Ouro, café, } \\
\text { oleaginosas, } \\
\text { vegetais } \\
\text { comestíveis, } \\
\text { flores, animais } \\
\text { vivos, produtos de } \\
\text { couro, carne. }\end{array}$ & $\begin{array}{l}\text { Estados Unidos } \\
(9,7 \%) \\
\text { Arábia Saudita } \\
(9,6 \%) \\
\text { Alemanha (8,5\%) } \\
\text { Suíça (7,5\%) } \\
\text { China (5,1\%) } \\
\text { Emirados Árabes } \\
\text { Unidos (4,9\%) } \\
\text { Paquistão (4,4\%) }\end{array}$ & $\begin{array}{l}\text { Maquinário e ae- } \\
\text { ronaves, metais, } \\
\text { materiais elétri- } \\
\text { cos, derivados de } \\
\text { petróleo, veículos } \\
\text { automotores, } \\
\text { produtos quími- } \\
\text { cos, fertilizantes. }\end{array}$ & $\begin{array}{l}\text { China }(28,8 \%) \\
\text { Estados Unidos } \\
(8,0 \%) \\
\text { Índia }(6,7 \%) \\
\text { Kuwait }(5,0 \%)\end{array}$ \\
\hline Quênia & $\begin{array}{l}\text { Chá, produtos } \\
\text { hortícolas, café, } \\
\text { derivados de } \\
\text { petróleo, peixe, } \\
\text { cimento. }\end{array}$ & $\begin{array}{l}\text { Uganda (10,1\%) } \\
\text { Tanzânia (8.6\%) } \\
\text { Estados Unidos } \\
(7,7 \%) \\
\text { Holanda }(7,4 \%) \\
\text { Reino Unido (7,3\%) } \\
\text { Paquistão (4,5\%) } \\
\text { Emirados Árabes } \\
\text { Unidos (4,6\%) }\end{array}$ & $\begin{array}{l}\text { Maquinário, } \\
\text { equipamentos } \\
\text { de transporte, } \\
\text { derivados de } \\
\text { petróleo, veículos } \\
\text { automotores, fer- } \\
\text { ro e aço, resinas } \\
\text { e plásticos. }\end{array}$ & $\begin{array}{l}\text { China }(24,1 \%) \\
\text { Índia }(11,2 \%) \\
\text { Emirados } \\
\text { Arabes Unidos } \\
(7,7 \%) \\
\text { Japão }(5,4 \%)\end{array}$ \\
\hline
\end{tabular}

Fonte: Elaboração própria a partir de United States of America (2017).

Nota: As informações fazem referência ao ano de 2016, com exceção das referentes às exportações da Nigéria, que são do ano de 2012. 
Em uma breve análise de cada um dos países, vê-se como a Nigéria - considerada desde 2014 a maior economia africana - é extremamente dependente do setor extrativista focado em suas grandes reservas de petróleo. A indústria representa quase um quinto do $\mathrm{PIB}^{4}$ nigeriano, sendo grande parte em função da indústria extrativa - petróleo, carvão, estanho - e, em menor escala, de têxteis e materiais de construção. Além disso, suas exportações se dedicam quase totalmente ao petróleo, e o país importa bens de capital, na tradicional divisão norte-sul. Apesar dos grandes retornos do petróleo e crescimento econômico, $70 \%$ da força de trabalho está alocada no setor agrícola e mais de $62 \%$ da população vive em extrema pobreza (UNITED STATES OF AMERICA, 2017).

Na África do Sul, o extrativismo também tem participação expressiva na indústria, com foco na mineração. Apesar disso, a África do Sul tem uma economia mais diversificada que a maioria das africanas, destacando-se não apenas a sua abundância de recursos naturais, mas também os setores financeiro, de comunicações, de energia e de transportes. O setor industrial, além do extrativismo, também apresenta montagem de veículos, metalurgia, maquinário, têxteis, ferro e aço. Seus principais parceiros comerciais são a China, Alemanha e Estados Unidos (UNITED STATES OF AMERICA, 2017).

No Sudão, ${ }^{5}$ muito embora a exploração de petróleo contribua muito para o PIB, mais de dois terços da população se dedica à agricultura de subsistência, sendo que quase metade dos sudaneses se encontra abaixo da linha de pobreza. A indústria sudanesa se restringe ao petróleo, agroindústria algodoeira e açucareira, têxteis, cimento, sapatos, armamentos, entre outros, e às exportações a esses mesmos produtos, em adição de outros recursos naturais como o ouro (UNITED STATES OF AMERICA, 2017).

A Angola cresceu muito nos últimos anos em função da produção de petróleo, sendo esse setor responsável por 50\% do PIB angolano. O país tem como principais bens de exportação produtos primários e importa bens de maior valor agregado, como maquinário, equipamentos elétricos e veículos automotores. O seu principal parceiro comercial é a China. A maior parte da população trabalha com a agricultura, entretanto metade dos alimentos em Angola ainda é importado (UNITED STATES OF AMERICA, 2017).

Enquanto isso, na Etiópia, mais de $80 \%$ da população encontra-se empregada no setor agrícola. No setor industrial, destaca-se a indústria agroalimentar, de bebidas, têxteis, couro, químicos, processamento de metal, cimento. O café tem grande peso nas exportações, além de outras commodities. O setor de serviços da

$4 \quad$ Para fins de comparação, apresenta-se a porcentagem da indústria no PIB de outros países: China 39,8\%, Alemanha 30,3\%, Japão 29,6\%, França 19,6\%, Reino Unido 19,2\%, Estados Unidos 18,9\% (UNITED STATES OF AMERICA, 2017).

5 A secessão do Sudão do Sul, em 2011, causou ao Sudão a perda de três quartos de sua produção de petróleo, além das consequências da guerra civil e dos conflitos subsequentes que também abalaram fortemente a economia sudanesa. 
Etiópia se destaca, com ênfase nas companhias aéreas, encontrando-se em suas importações maquinário e peças de avião, produtos metalúrgicos, materiais elétricos e petróleo (UNITED STATES OF AMERICA, 2017).

Por fim, o Quênia tem como atividade principal da sua população a agricultura, majoritariamente de caráter familiar e de pequena escala. O setor industrial se restringe a bens de consumo de pequena escala, agroindústria e extrativismo. As exportações são basicamente dos produtos recém citados, além do petróleo (UNITED STATES OF AMERICA, 2017).

A partir da esquematização do perfil desses seis países, é possível fazer algumas constatações. Inicialmente, a economia da África do Sul tem características completamente distintas das economias dos outros cinco países. Esse país figura como exceção à regra. Registra baixíssima contribuição da agricultura no PIB e na alocação da força de trabalho nesse setor, além de economia mais diversificada. Como citado anteriormente, o setor industrial sul-africano é mais robusto, com a produção de bens de maior valor agregado. A África do Sul integra o rol dos países emergentes, sendo inclusive membro dos Brics. Dessa forma, o presente estudo considera a economia sul-africana como já convertida inteiramente em economia capitalista, necessitando, portanto, de expansão externa para se desenvolver. Isso é evidenciado, inclusive, pela posição sul-africana dentro do continente, que é de exportadora de bens industrializados para seus vizinhos.

O primeiro ponto comum que se destaca nos demais cinco países é que, em todos, o extrativismo corresponde a grande parte do setor industrial, destacando-se, principalmente, a indústria petrolífera, além de outros minerais. Nesse esquema, os setores industriais dos países são em geral muito especializados, havendo pouco incentivo para a diversificação ou maior complexificação da produção, assemelhando-se a uma economia mercantil.

O segundo ponto comum é que a agricultura, apesar de não ser tão expressiva no PIB, ainda figura como maior setor de alocação da força de trabalho, grande parte como agricultura familiar. Nessa situação, essa população tem renda muito baixa e os índices de pobreza são muito altos. Esse tipo de produção se assemelha ao que é descrito, por Rosa Luxemburgo, como as economias naturais pré-capitalistas, em que se produz para a própria necessidade doméstica.

O terceiro ponto é que é recorrente o tradicional padrão de comércio norte-sul entre os países analisados e seus parceiros comerciais. Os países africanos citados têm como principais produtos de exportações bens primários, com destaque para os recursos naturais, enquanto importam bens de maior valor agregado, como maquinário, equipamento elétrico, automóveis e bens manufaturados. Esse aspecto também é compartilhado pela África do Sul.

Por fim, chama a atenção o fato de que, entre os produtos de maior relevância nas importações desses países africanos, encontram-se justamente os bens de trans- 
porte, que juntamente com bens de comunicação, Rosa Luxemburgo considerava como setores vitais para a difusão do capitalismo em regiões de economias naturais.

Dessa maneira, é possível estabelecer um paralelo entre a teoria de Rosa Luxemburgo da acumulação primitiva continuada e a situação dos seis países africanos estudados. A África, e em especial a África subsaariana, tem sido constantemente explorada, tanto seus recursos naturais como mão de obra e mercados, por forças externas que visam o próprio crescimento e pouco contribuem para o desenvolvimento africano. A exploração da África desde o capitalismo mercantil enriqueceu o centro capitalista e ainda hoje essa relação de submissão é evidenciada. A partir da posição de exportador de commodities, o continente africano se submete ao mercado capitalista internacional e por este é explorado, em uma continuada manutenção das relações imperialistas do século XIX.

\section{Considerações Finais}

A África é um continente extremamente rico, com grande diversidade de culturas, línguas, religiões, etnias e organizações sociais - não é apenas sobre as riquezas naturais que o berço da humanidade se estabeleceu. Além disso, o território tem destaque estratégico, a partir de sua posição geopolítica. O século XXI e a atual correlação de forças mundiais ressaltaram a África como região estratégica, com grande potencial de crescimento e atuação no sistema internacional.

Entretanto, assim como no século XIX, ainda hoje se percebe como as decisões externas incidem fortemente na África. Em função de tudo o que o continente já passou, registra-se, ainda atualmente, a grande fragilidade econômica, que, aliada à vulnerabilidade política, o coloca numa situação de suscetibilidade externa. Essa posição do continente no mercado global é mantida pelas relações imperialistas que existem entre os países africanos e as grandes potências mundiais e, à medida que beneficiam o centro capitalista, tendem a se aprofundar cada vez mais sem contribuir para o desenvolvimento africano.

A teoria de Rosa Luxemburgo consiste na constatação de que o capitalismo precisa estar em constante expansão para o próprio desenvolvimento, tirando das regiões exploradas os recursos para o próprio fomento, além de estabelecer formas de acumulação no local explorado. A África hoje se configura basicamente como exportadora de produtos primários, estritamente ligada a países de economias mais fortes, em laços comerciais que podem ser denominados de Neocolonialismo - continuidade do imperialismo sem a dominação formal. O crescimento que o mercado global provê à região é aquele direcionado para fora, que não desenvolve internamente. Ademais, o continente fica extremamente dependente das flutuações dos mercados internacionais de commodities. 
Além disso, através do estudo de seis países selecionados, constata-se como a introdução do capitalismo na África a faz ter diferentes estágios de desenvolvimento. Enquanto existem áreas cujo modo de produção é capitalista e estão integradas ao mercado global, também se registra áreas com formações menos complexas, de economia mercantil e, inclusive, formas de produção não capitalistas. Esta identifica-se nas economias rurais simples, de subsistência e agricultura familiar, as quais não estão integradas a mercados capitalistas. Dessa maneira, registra-se um processo de introdução do capitalismo nos países africanos que não é homogêneo, mas que, aos poucos, vêm tomando conta do continente em função de haver nessa região possibilidade de acumulação pelo capitalismo central.

A partir disso, percebe-se como o imperialismo é um referencial teórico extremamente útil para entender não apenas a história da África, mas também suas dinâmicas atuais. Ao se trazer a teoria do imperialismo de Rosa Luxemburgo para os dias de hoje, é possível identificar laços imperialistas informais que continuam modelando e restringindo o comportamento de países mais fracos do sistema internacional. A grande influência externa retira dos governos a capacidade de promover o desenvolvimento interno, ou seja, as relações imperialistas impedem a ação autônoma dos Estados africanos. Portanto, o imperialismo e a teoria de Rosa Luxemburgo, por consequência, são ainda hoje muito atuais e um campo de estudos e pesquisa abrangente dentro das Relações Internacionais e da Economia.

\section{Referências}

BRACKING, S.; HARRISON, G. Africa, imperialism $\mathcal{E}$ new forms of accumulation. Review Of African Political Economy, v. 30, p. 5-10, 2003.

BUSH, R.; SZEFTEL, M. Commentary: bringing imperialism back in. Review of African Political Economy, n. 80, p. 165-169, 1999.

HARVEY, D. O novo imperialismo. São Paulo: Loyola, 2013.

HUNT, E. K. História do pensamento econômico: uma perspectiva crítica. Rio de Janeiro: Elsevier, 2005. p. 340-347.

KRIPPENDORFF, E. A história das relações internacionais. Lisboa: Antídoto, 1979.

LEE, M. C. The 21st century scramble for Africa. Journal of Contemporary African Studies, v. 24, n. 3, p. 303-330, 2006. Disponível em: https://www.tandfonline.com/doi/ abs/10.1080/02589000600976570. Acesso em: 17 fev. 2020.

LEE, M. C. Trade relations between the European Union and Sub-Saharan Africa under the cotonou agreement: repartitioning an d economically recolonising the continent? In: SOUTHALL, R.; MELBER, H. A new scramble for Africa? Imperialism, investment and development. Scottsville: University Of Kwazulu-natal Press, 2009. p. 83-110. 
LUXEMBURGO, R. A acumulação do capital: estudos sobre a interpretação econômica do imperialismo. Rio de Janeiro: Zahar, 1970. p. 317.

MARIUTTI, E. B. Interpretações clássicas do imperialismo. Texto para discussão - Instituto de Economia da UNICAMP, n. 216, 2013.

MELBER, H. Global trade regimes and multi-polarity: the US and Chinese scramble for African resources and markets. In: SOUTHALL, R.; MELBER, H. A new scramble for Africa? Imperialism, investment and development. Scottsville: University Of Kwazulu-natal Press, 2009. p. 56-82.

MIGLIOLI, J. Acumulação de capital e demanda efetiva. São Paulo: T. A. Queiros, 1981.

ROBINSON, J. Introduction. In: LUXEMBURG, R. The accumulation of capital. London: Routledge and Kegan Paul LTD, 1951. Disponível em: https:/www.marxists.org/archive/luxemburg/1913/accumulation-capital/accumulation.pdf. Acesso em: 08 nov. 2017.

SARAIVA, J. F. S. A África no século XXI: um ensaio acadêmico. Brasília: Fundação Alexandre de Gusmão, 2015.

SATGAR, V. Global capitalism and the neo-liberalisation of Africa. In: SOUTHALL, R.; MELBER, H. A new scramble for Africa? Imperialism, investment and development. Scottsville: University of Kwazulu-natal Press, 2009, p. 35-55.

SINGER, P. Apresentação. In: LUXEMBURG, R. A acumulação do capital: estudos sobre a interpretação econômica do Imperialismo. São Paulo 1984. (Coleção os Economistas, v. 1)

SOUTHALL, R.; COMNINOS, A. The scramble for Africa and the marginalisation of African capitalism. In: SOUTHALL, R.; MELBER, H. A new scramble for Africa? Imperialism, investment and development. Scottsville: University Of Kwazulu-natal Press, 2009, p. 357-385.

SOUTHALL, R.; MELBER, H. A new scramble for Africa? Imperialism, investment and development. Scottsville: University Of Kwazulu-natal Press, 2009.

UNITED STATES OF AMERICA. Central Intelligence Agency. The World Factbook. 2017. Disponível em: https:/www.cia.gov/library/publications/the-world-factbook/. Acesso em: 30 out. 2017.

VISENTINI, P. F.; CEBRAFRICA EQUIPE. A África e as potências emergentes: nova partilha ou cooperação sul-sul? Porto Alegre: Leitura XXI, 2013.

Recebido em: 05/12/2017.

Aceito em: 13/06/2018.

(cc) BY 